\title{
Simulation as Implementation of Digital Approach to Decision- Making under Uncertainty and Risk
}

\author{
$O . V$. Tiutyk $^{1, *}$ and M.E. Butakova \\ *Corresponding author: tyutyk@mail.ru \\ ${ }^{1}$ Perm State National Research University, Perm, Russia \\ ${ }^{2}$ Perm National Research Polytechnic University, Perm, Russia
}

\begin{abstract}
The paper articulates the problem of modeling management decision-making process in new digital reality: decision-making under uncertainty, volatile environment, huge amount of data to be accounted, objective analytical risk attitude. The proposed solution includes critical selection of risk and uncertainty management tools aimed at improvement quality of management decision-making information support in the sustainable development context (on the example of construction projects).

The aim of research is the development of the new "digital" approach to the process of reducing uncertainty when decision making in highly risk projects, including the process model and toolkit.

Methodology is based on logical analysis and synthesis, decomposition, qualitative analysis of the relevant literature and primary data (top management informal interviews, targeted sample), comparative and regression analysis, time series analysis, mathematical statistics and simulation modelling based on nine sets of design estimation paperwork and turnover-balance sheets.

The contribution into the existing knowledge includes substantiating the correlation of the terms of the digital decision-making and simulation modeling tools in high-risk projects management under insufficient statistical data and their mutual interaction. Also, advisability of formalization of the decisionmaking method based on unprocessed design estimates is justified, and appropriate methods for sustainable decision-making information support are selected. The approbation demonstrated practical significance and economic effectiveness of developed approach; experiment was carried out on the base of «RSU - 6» LLC's projects (Tchaikovsky, Perm region).
\end{abstract}

Key words: uncertainty, high-risk projects, digitalization, digital decision-making, simulation modeling, management model.

\section{Introduction}

Decision-making under uncertainty is linked to impossibility to assign a probability to future states of nature [1]. In this case, a decision-maker is guided by his/her risk preferences reflected by decision-making criteria, such as Wald, Maximax, Hurwitz, criterion of Savage, Laplace or others. However, the efficiency of these criteria is rather low, especially in short and medium terms, mostly relevant for project management [2]. The choice of a decision-making criterion is the most difficult and responsible step, and there are no universal recommendations. In fact, such an approach simply reflects decision-maker's personal risk attitude. In general, it gives an illusion of objective justification, since the matrix contains a finite, and relatively small, number of possibilities, while in reality the number of possible states of nature is usually infinite [3]. Consequently, in the vast majority of cases, it seems to be rational to make some efforts to reduce decision-making under uncertainty to decision-making under risk. Thus, it is necessary to find a way to assess probabilities of future states of nature. Some authors believe that the probabilistic approach is justified and efficient only when the input parameters are determined by large amounts of representative statistics, and, in reality, generalising the results of a study on certain sample to the entire population is not always correct. However, there is also an opinion that, presuming proper application, even subjective probability estimations, especially those processed in a certain way, can reduce uncertainty in decision-making [4,5].

\section{Problem Statement}

In practice, a significant number of management decisions, especially major, complex ones, are made using heuristic methods and intuition. But some of these decisions could be comparatively easily mathematically formalised and processed, that usually gives more adequate and less distorted results [6]. However, many managers are sceptical on business intelligence aids ability to reduce uncertainty. In Russia, compared with Western countries, the level of scepticism is somewhat higher [7]; most likely, it can be explained by attempts to transfer Western companies' methods directly without national specifics consideration. Among the reasons for unwillingness to use mathematical statistics combined with expert opinions in their work, managers of Russian companies usually name:

- impossibility to get an exact result because of errors, rounding and approximation; 
- distrust to statistics or its insufficiency;

- complexity of methods' application, difficulties of interpretation for non-specialists;

- lack of qualified specialists.

However, acting solely on the basis of intuition is wrong. Quite the reverse, managers should systematize both already known information, and information that potentially could be obtained. Even if analysis of aggregated information would not result in a meaningful forecast of possible solutions, managers still get a general idea of the future [8]. Hence, there is a need to justify the following points:

- approximate results, meaning not a complete uncertainty elimination, but its reduction, are also valuable;

- some uncertainty reduction does not require lots of data, especially when the uncertainty is high;

- both formal data and processed experts' opinions can be used;

- there are simple to use but efficient tools that produce easy to understand results if applied correctly.

That determines the problem of this article and the logical scheme of research:

1) development of the digital approach to management process of decision-making under uncertainty and risk, proceeding the primary intuitive (personal experience and unstructured data based) and the following analytical (modeling and extrapolation based) approaches;

2) development of infrastructure for implementation of digital approach to decision-making;

3) application of simulation as fundamental toolkit in digital decision-making.

The stated problem allows the authors to distinguish the research questions.

\section{Research Questions}

This paper logically combines and elaborates the following fields of knowledge:

- management decision-making under uncertainty and risk, analytical approach and formalization as a mean of its quality improvement;

- $\quad$ data warehouse (DWH) as the key infrastructural foundation for business intelligence (BI) systems;

- $\quad$ selection of optimal tools for implementation of the offered approach and their testing.

Synthesis of the named aspects results into a coherent well-rounded management (decision-making) digitalized model accommodating business needs in the volatile environment.

\section{Purpose of the Study}

The aim of research is the development of the new "digital" approach to the process of reducing uncertainty when decision making in highly risk projects, including the process model and toolkit. The objectives:

- to distinguish relevant aspects of management decision-making under uncertainty and risk, and to critically assess possible ways of its quality improvement in the context of digitalization focusing on formalization;

to consider DWH as the key infrastructural foundation for digitalization at the micro-level providing the management with broad opportunities for simulation modeling under uncertainty and lack of data;

to investigate correlation of the terms of digital decision-making and simulation modeling tools in high-risk projects management under insufficient statistical data and their mutual interaction;

to justify formalization as a base for high quality sustainable decision-making and select appropriate methods for information support;

to synthesize the named aspects into a coherent well-rounded management (decision-making) digitalized model accommodating business needs in the volatile environment.

to test the developed approach to validate its practical significance and effectiveness.

According to the stated purpose broad range of qualitative and quantitative management research methods should be elaborated and used.

\section{Research Methods}

Methodology is based on logical analysis and synthesis, decomposition, qualitative analysis of the relevant literature and primary data (top management informal interviews, targeted sample), comparative and regression analysis, time series analysis, mathematical statistics, simulation modeling and Monte Carlo simulations based on nine sets of design estimation paperwork and turnover-balance sheets provided by «RSU - 6» LLC. The detailed methodology is presented in the connected papers $[9,10]$. 


\section{Findings}

Modern volatile business environment, direct proportion between a project's risk and profitability levels and informational overloads determine managers transfer from primary intuitive approach (personal experience and unstructured data based) and the following analytical one (modeling and extrapolation based) [11], to digital decisionmaking [12]. Literature review prove the validity of these statements [13, 14].

Historically the most natural decision-making approach is based on managers personal experience, intuition and, sometimes, fragmented data. The key role in decision-making belonged to the manager and his/her personal competencies [11].

Analytical approach to products, customers and the business environment allows a company to forecast the demand structure and decrease uncertainty. The design of this system should reflect the whole range of currently disintegrated business processes, provide effective data processing tools and present contextually relevant information in an easily understandable way. A common informational space is likely to increase the levels of data accessibility and transparency $[15,16]$.

Current trends and newest technological solutions give managers opportunity to accumulate and process enormous amounts of data. Adequate realization of this opportunity brings certain advantages in high-risk projects decisionmaking under volatile completive environment. Consequently, economy digitalization brings certain benefits at the micro level. However, the obstruction of its wide implementation in companies lays in the management field. That leads to the need of a management model that would logically combine BI (data-driven) approach and the social and psychological needs and features of personnel [17]. The development of approaches to decision-making process under uncertainty and risk is presented at Figure 1.

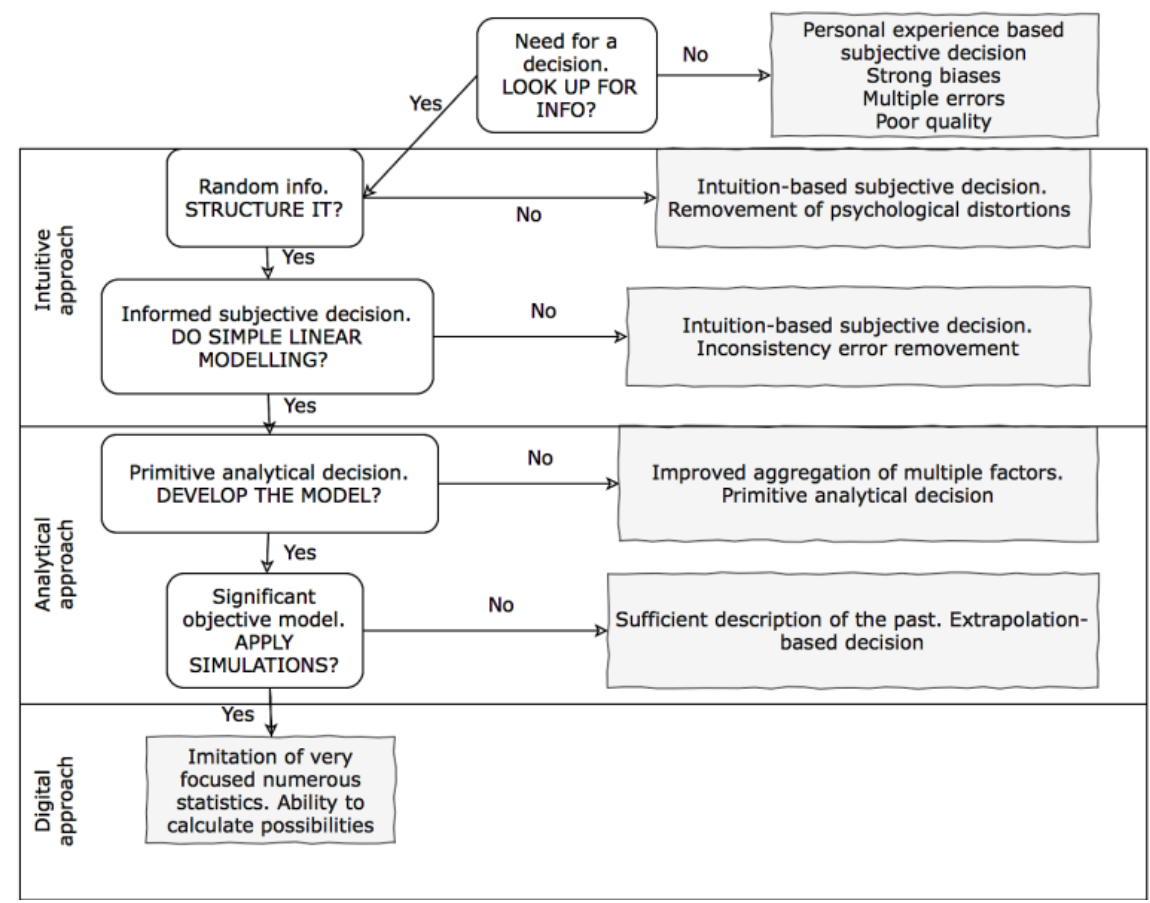

Figure 1. Evolution of decision-making approaches (Source: compiled by the authors)

Digital approach is considerably based on analytical one, sharing the same infrastructure (means of data, collection, accumulation, transition, processing, etc.). Development of infrastructure and environment features for implementation of digital approach to decision-making starts with examination of the term "DWH".

DWH is widely discussed in academic circles since 1990's. Its concepts are developed and analyzed in a range of works, and this paper is based on the articles that represent the needed balance of technical and managerial view [5, 1820]. Presently, DWH is recognized as a key infrastructural foundation for most enterprise level BI systems [20]. The synthetic definition of DWH can be formulated as a subject-oriented, integrated, time-variant and non-volatile collection of data [20] incorporated into a consistent form to deliver ' 360 degrees' observation of the organization. That includes collecting data from various sources, its processing and forming a homogenous easily manipulated body of data. This definition articulates not only the system but also data quality parameters that will be discussed later. The process of a DWH development and implementation is usually complex and continuous. It can be examined from different perspectives, and this paper investigates the managerial one. From the managerial view, the whole development and implementation process can be described at figure 2. The detailed explanation of the presented figure is given in previous works [21]. 


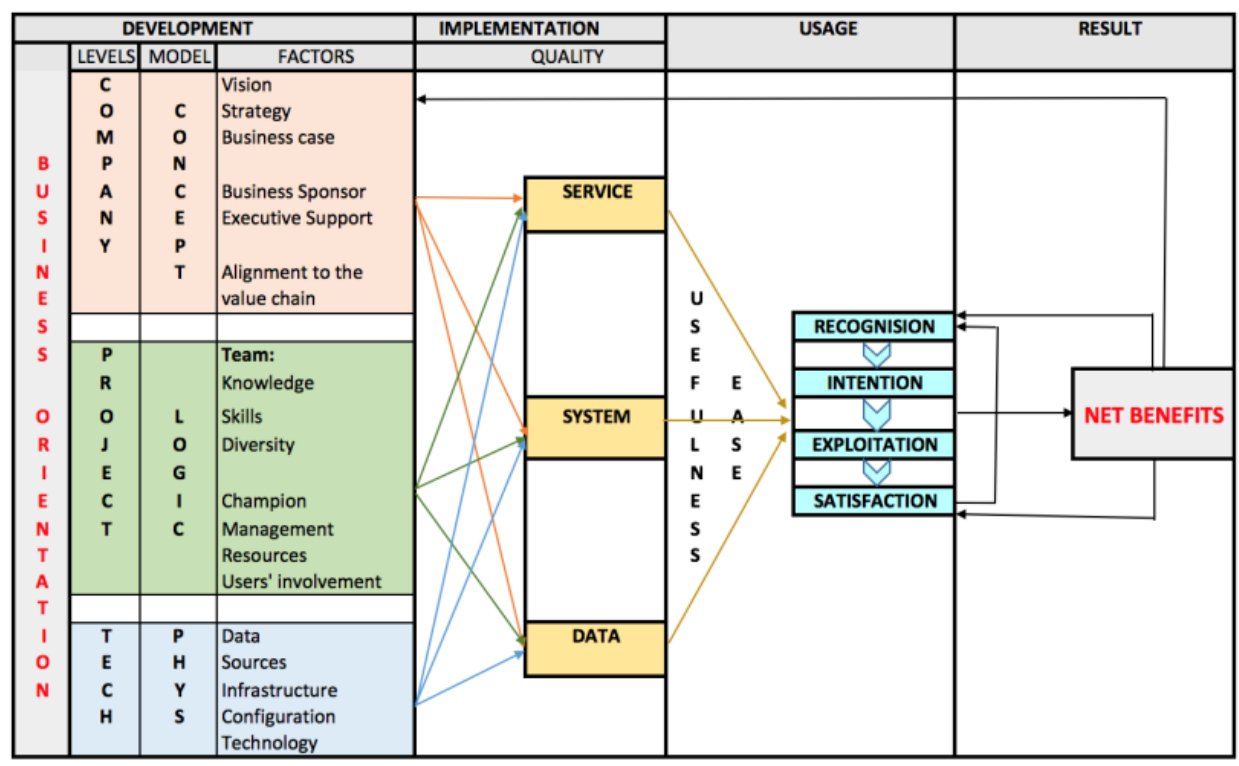

Figure 2. DWH development and implementation factors (Source: compiled by the authors)

The function of DWH as informed strategically oriented decision-making support determines the major requirement to the system as Business (company) Orientation [22]. Moreover, a wide range of previous studies proves that in terms of the success factors the non-technical factors tend to be more influential comparing to technical ones [5].

If the positive impact of the DWH usage on the performance is recognized among the staff, people tend to embrace the new practice more willingly. Less efforts are required to use the system, the more efficient and satisfactory for an individual it is. That motivates people to use and develop the DWH, supplementing it with extra clear relevant data.

Application of simulation as fundamental toolkit in digital decision-making underlines the idea that digital approach does not conflict, but organically improves the analytical one. In other words, analytical approach is enhanced with the newest technological achievements of digital era. As an example of a practical use of the proposed approach a model for uncertainty reduction in construction projects decision-making was developed. The model is based on standard simulation modeling techniques and Monte Carlo simulations; the process of its building is presented in previous papers [10]. As a result of the model run, a user obtains statistically justified probabilities of particular results, that is, decisionmaking under uncertainty is reduced to decision-making under risk (figure 3). Notably, this transformation is more realistic in comparison with widely used Laplace criterion.

\section{Probability, \%}

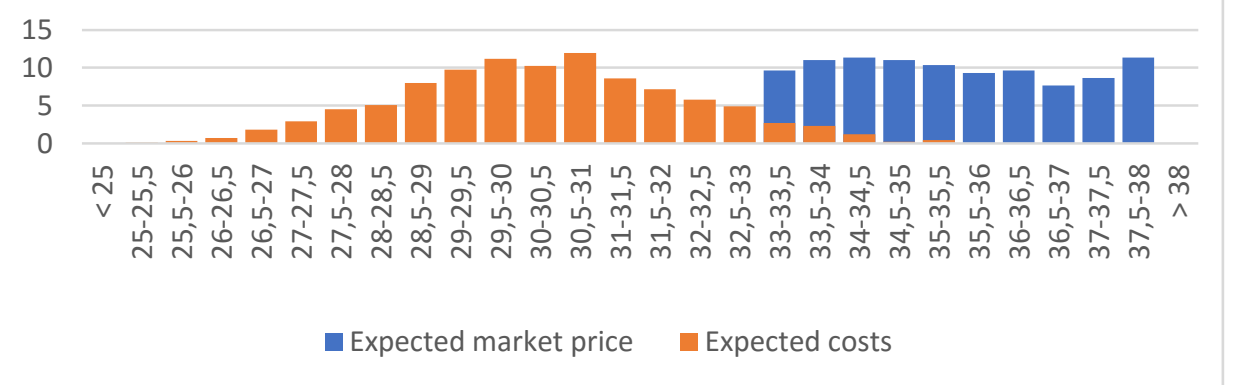

Figure 3. Probability distribution (Source: compiled by the authors)

The presented management model is based on active collection and use of the available information. It includes certain advantages of big data, data-mining and some other tools of BI, while staying focused on the human factor as the core of any company.

\section{Conclusion}

Synthesis of the researched aspects results into a coherent well-rounded management (decision-making) digitalized approach accommodating business needs in the volatile environment, which could be effectively implemented through simulation under uncertainty and risk. 
The contribution into the existing knowledge includes substantiating the correlation of the terms of the digitalization and simulation modeling tools in high-risk projects management under insufficient statistical data and their mutual interaction. The paper articulates the term "digital decision-making" meaning management approach that logically combines Business Intelligence (data-driven) approach and the social and psychological needs and features of personnel. That becomes possible with the newest technological achievements in the fields of big data and data-mining.

Data warehouse was justified as the key infrastructural foundation for digitalization at the micro-level providing the management with broad opportunities for simulation modelling under uncertainty and lack of data.

Appropriate methods of providing information support for digital decision-making are determined. Application of simulation as fundamental toolkit in digital decision-making underlines the idea that digital approach does not conflict, but organically improves the analytical one. In other words, analytical approach is enhanced with the newest technological achievements of digital era. The approbation demonstrated practical significance and economic effectiveness of the developed approach; experiment was carried out on the base of «RSU - 6» LLC's projects, Tchaikovsky, Perm region.

As a possible future development of the article's ideas testing of digital decision-making in high-risk projects of other industries. Another aspect of future research is further development of system digital decision-making methodology under uncertainty and risk.

\section{References}

1. D. Kahneman, A. Tversky, Prospect theory: An analysis of decision under risk. Econometrica, 47(2), 263-292. DOI: 10.2307/1914185 (1979).

2. A.Yu. Chepurenko, Entrepreneurship theory: New challenges and future prospects. Foresight-Russia, 9(2), 44-57. DOI: 10.17323/1995-459x.2015.2.44.57 (2015).

3. T.D. Malyutina, Methods of decision making under different levels of uncertainty. Management of Economic Systems, 12(60). URL: https://cyberleninka.ru/article/n/metody-prinyatiya-upravlencheskih-resheniy-pri-raznyhurovnyah-neopredelennosti (2013). [in Rus.].

4. K. Haegeman, E. Marinelli, F. Scapolo, A. Ricci, A. Sokolov, Quantitative and qualitative approaches in FTA: from combination to integration? Technological Forecasting and Social Change, 80(3), 386-397. DOI: 10.1016/j.techfore.2012.10.002 (2013).

5. B.H. Wixom, H.J. Watson, An empirical investigation of the factors affecting data warehousing success. MIS Quarterly: Management Information Systems, 25(1), 17-41. DOI: 10.2307/3250957 (2001).

6. N. Mikova, A. Sokolova, Global technology trends monitoring: theoretical frameworks and best practices. Foresight-Russia, 8(4), 64-83 (2014).

7. S.P. Aukuzionek, Investment behavior of enterprises in 2015-2016. Russian Economic Barometer, 3(63), 3-10. URL: https://cyberleninka.ru/article/n/investitsionnoe-povedenie-predpriyatiy-v-2015-2016-gg (2016). [in Rus.].

8. T.U. Korneeva, S.A. Nikitin, Formation of strategy of development of industrial enterprises in the conditions of uncertainty. News of Tula State University. Economic and Legal Sciences, 2(2), 136-142. URL: https://cyberleninka.ru/article/n/formirovanie-strategii-razvitiya-promyshlennyh-predpriyatiy-v-usloviyahneopredelennosti (2009). [in Rus.].

9. I.M. Golova, A.F. Sukhovey, Threats to the innovative security of regional development in a digital society. Economy of Region, 14(3), 987-1002. DOI: 10.17059/2018-3-21 (2018). [in Rus.].

10. T.Y. Prasolova, M.E. Butakova, The model for design estimates documentation processing aimed at management decision-making informational support in construction projects in Russian Federation. Competitiveness in the Global World: Economics, Science, Technology, 11(6), 779-783. URL: https://docs.wixstatic.com/ugd/dcaed9 b4b26b8acc1d4050a80f4cf4515ff23c.pdf (2017). [in Rus.].

11. Lipatov, B.V. The new management indication: from history to innovation. Bulletin of Peoples' Friendship University of Russia. Series: Sociology, 2, 46-52. URL: https://cyberleninka.ru/article/n/novoe-izmenenie-upravleniya-ot-istorii-kinnovatsiyam (2008). [in Rus.].

12. D. Gorissen, I. Couckuyt, D. Demeester, T. Dhaene, K. Crombecq, A surrogate modeling and adaptive sampling toolbox for computer based design. Journal of Machine Learning Research, 11, 2051-2055 (2010).

13. A. Giglavy, A. Sokolov, G. Abdrakhmanova, A. Chulok, V. Burov, Long-term trends in the ICT sector. ForesightRussia, 7(3), 6-24. DOI: 10.17323/1995-459X.2013.3.6.24 (2013).

14. S.Y. Glazyev, Anti-crisis strategy of the Russian economy development in the XXI century. Economy of Region, 2(30), 10-25. DOI: 10.17059/2012-2-1 (2012). [in Rus.].

15. J. Calof, G. Richards, J. Smith, Foresight, competitive intelligence and business analytics - tools for making industrial programmes more efficient. Foresight-Russia, 9(1), 68-81. DOI: 10.17323/1995-459x.2015.1.68.81 (2015).

16. L. Gokhberg, A. Sokolov, Targeting STI policy interventions - future challenges for foresight. In D. Meissner, L. Gokhberg, A. Sokolov (Eds.) Science, technology and innovation policy for the future: Potentials and limits of foresight studies (pp. 289-292). New York: Springer (2013).

17. A. Apokin, D. Belousov, V. Salnikov, I. Frolov, Long-term socioeconomic challenges for Russia and demand for new technology. Foresight and STI Governance, 9(4), 6-17. DOI: 10.17323/1995-459x.2015.4.6.17 (2015). 
18. F.D. Davis, Perceived usefulness, perceived ease of use, and user acceptance of information technology. MIS Quarterly: Management Information Systems, 13(3), 319-339 (1989).

19. W. DeLone, E. McLean, Information systems success: The quest for the dependent variable. Information Systems Research, 3(1), 60-95. DOI: 10.1287/isre.3.1.60 (1992).

20. W. Yeoh, A. Koronios, Critical success factors for business intelligence systems. Journal of Computer Information Systems, 50(3), 23-32. URL: https://pdfs.semanticscholar.org/7a66/7cdb124e404be1f0152260eade99b1f8d217.pdf (2010).

21. T.Y. Prasolova, M.E. Butakova, O.V. Tiutyk, Managerial aspects of data warehousing development and implementation at housing construction enterprises of the Russian Federation based on the international practice. Competitiveness in the Global World: Economics, Science, Technology, 4(1), 27-34. URL: https://docs.wixstatic.com/ugd/dcaed9_e4db083c38d0424cb70de607e7f05a50.pdf (2018). [in Rus.].

22. B.L. Cooper, H.J. Watson, B.H. Wixom, D.L. Goodhue, Data warehousing supports corporate strategy at first American corporation. MIS Quarterly: Management Information Systems, 24(4), 547-567 (2000). 